\title{
Moyamoya Disease in a Member of the Roma Gypsy Community
}

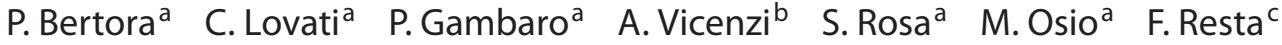 \\ C. Mariania \\ ${ }^{a}$ Chair of Neurology, Department of Clinical Sciences, Università degli Studi di Milano, and Departments of \\ ${ }^{b}$ Internal Medicine and ' Imaging Diagnostics, L. Sacco Hospital, Milano, Italy
}

\section{Dear Sir,}

Moyamoya disease is a clinical entity in which occlusion of intracranial large vessels, in particular carotid arteries, occurs in association with the development of an abnormal vascular network within the brain, especially in the basal ganglia. Clinical manifestations include hemiplegia of sudden onset, symptoms of intracranial bleeding and seizures [1]. Seven to $10 \%$ of cases occur with familial clustering, with variable patterns of inheritance (more often autosomal dominant with incomplete penetrance) $[2,3]$. The disease, although present throughout the world, has a particularly high incidence in Eastern Asia, particularly in Japan [4], as well as within close communities all around the world, such as the Amish and Mennonites. We describe the occurrence of moyamoya disease in a member of the community of Roma gypsies.

\section{Case Report}

A 36-year-old woman presented to the hospital ward for sudden appearance of a left sensorimotor defect. The patient belonged to the ethnic group of Roma gypsies, a population originating from Eastern Europe and present in Italy as well as in many European countries, and had been living in Italy since birth. The patient's parents had died at a young age for unknown causes. A patient's sister had died before the age of 30 of cerebral haemorrhage (not further investigated), and a patient's son a heterozygote twin - had died soon after birth for unknown causes. A brain CT scan performed at admission showed several hypodense areas within the cerebral parenchyma in both hemispheres. Brain MRI confirmed the presence of multiple $\mathrm{T}_{1}$-hypointense and $\mathrm{T}_{2}$-hyperintense lesions lo- cated bilaterally in the cortex and deep white matter of the parietal and occipital lobes. The patient was then submitted to cerebral angiography and magnetic resonance angiography, which evidenced a picture consistent with moyamoya disease (fig. 1) [5]. The HLA genotype was A11, A24, B14, B15, DRB1-1, DRB1-11, DRB3. Laboratory analyses evidenced low protein

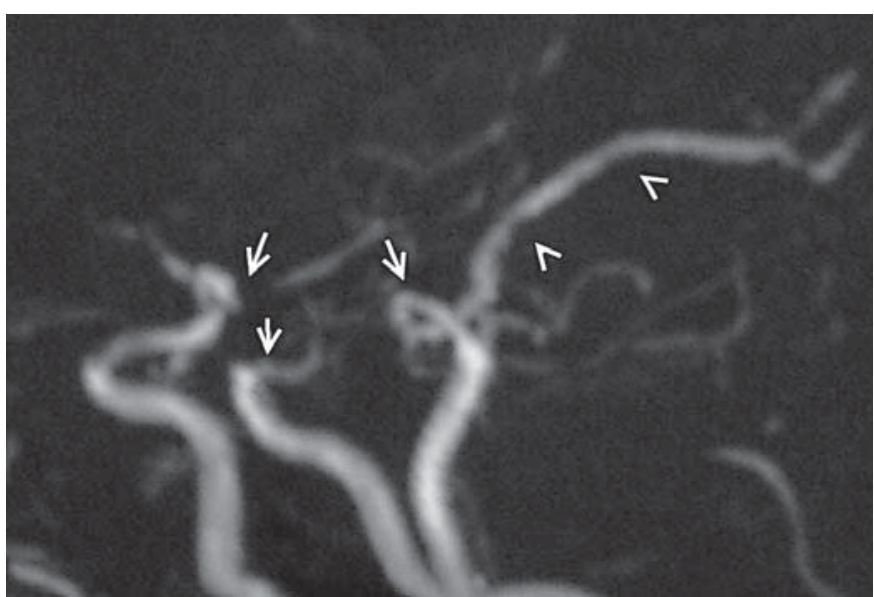

Fig. 1. Brain magnetic resonance angiography in the patient with moyamoya disease described in the text. The sudden narrowing of the right middle cerebral artery at the origin and the left internal carotid artery (arrows) and the absent visualization of the left posterior cerebral artery (arrowhead) are evidenced.

\section{KARGER}

Fax +41613061234

E-Mail karger@karger.ch

www.karger.com
(C) 2008 S. Karger AG, Basel 0014-3022/08/0595-0274\$24.50/0

Accessible online at: www.karger.com/ene
P. Bertora

Chair of Neurology, Department of Clinical Sciences

Università degli Studi di Milano, Via G.B. Grassi 74

IT-20157 Milano (Italy)

Tel. +39023904 2262, Fax +39025031 9867, E-Mail pierluigi.bertora@unimi.it 
S activity and an abnormal resistance to activated protein C. Keeping in mind the haemorrhagic risk of moyamoya disease, it was decided not to treat the patient with oral anticoagulants. Low-dose salicylate $(100 \mathrm{mg} /$ day) was therefore started, and the patient showed a near-complete recovery from the neurological syndrome described. Few months later she presented again for transient left superior homonymous quadrantopsia, again with spontaneous remission. No evidence of intracranial bleeding occurred on either occasion.

\section{Discussion}

Roma gypsies make part of a large population of probable Central Asian (Indian) ancestry, who migrated to Eastern Europe and further towards Western countries [6]. Within the Roma gypsies - as frequently occurs in culturally isolated communities - consanguinity between spouses is almost the rule and, as a consequence, genetically based diseases are often found. The more common diseases affecting, either directly or indirectly, the nervous system include heredodegenerative neuropathy, muscular dystrophy and coagulation disorders [7-9]. To date, this is the first report documenting the occurrence of moyamoya disease in the Roma gypsy ethnici- ty. The clinical and anamnestic data available, in particular the finding of a patient's close relative with fatal cerebral haemorrhage occurring at a young age, apparently suggest the presence of familial recurrence also in our case. The genetic background is likely to be different from that characterizing the East Asian cases, in whom a high occurrence of HLA-B51 is found [10]. Unfortunately, the peculiar cultural background of Italy-resident Roma gypsies (who live in complete isolation and even in strong conflict with the autochthonous community) hindered the collection of more detailed clinical information. It cannot be excluded, however, that misdiagnosed moyamoya disease may be responsible for a number of unexplained cerebral deaths within this community.

\section{References}

1 Gadoth N, Hirsch M: Primary and acquired forms of moyamoya syndrome: a review and three case reports. Isr J Med Sci 1980;16:370377.

2 Mineharu Y, Takenaka K, Yamakawa H, Inoue K, Ikeda H, Kikuta KI, Takagi Y, Nozaki $\mathrm{K}$, Hashimoto N, Koizumi A: Inheritance pattern of familial moyamoya disease: autosomal dominant mode and genomic imprinting. J Neurol Neurosurg Psychiatry 2006;77:1025-1029.
3 Seol HJ, Wang KC, Kim SK, Hwang YS, Kim KJ, Cho BK: Familial occurrence of moyamoya disease: a clinical study. Childs Nerv Syst 2006;22:1143-1148.

4 Ikezaki K, Inamura T, Kawano T, Fukui M: Clinical features of probable moyamoya disease in Japan. Clin Neurol Neurosurg 1997; 99(suppl 2):S173-177.

5 Yamada I, Nakagawa T, Matsushima Y, Shibuya H: High-resolution turbo magnetic resonance angiography in the diagnosis of moya-moya disease. Stroke 2001;32:18251831.

6 Kalaydjieva L, Morar B, Chaix R, Tang H: A newly discovered founder population: the Roma/Gypsies. Bioessays 2005;27:1084-1094.

7 Chandler D, Angelicheva D, Heather L, et al: Hereditary motor and sensory neuropathyLom (HMSNL): refined genetic mapping in Romani (Gypsy) families from several European countries. Neuromusc Disord 2000;10: 584-591.

8 Navarro C, Teijeira S: Neuromuscular disorders in the Gypsy ethnic group: a short review. Acta Myol 2003;22:11-14.

9 Balogh I, Poka R, Losonczy G, Muszbek L: High frequency of factor $\mathrm{V}$ Leiden mutation and prothrombin 20210A variant in Romanies of Eastern Hungary. Thromb Haemost 1999;82:1555-1556.

10 Aoyagi M, Ogami K, Matsushima Y, Shikata M, Yamamoto M, Yamamoto K: Human leukocyte antigen in patients with moyamoya disease. Stroke 1995;26:415-417. 